\title{
AN ANALYSIS OF ICT DEVELOPMENT STRATEGY FRAMEWORK IN CHINESE RURAL AREAS
}

\author{
Meiying Duan ${ }^{1, *}$,Martyn Warren ${ }^{2}$,Yunwen Lang ${ }^{1}$,Shaokun Lu ${ }^{1}$,Linnan \\ Yang \\ ${ }^{1}$ School of Information and Engineering, Yunnan Agricultural University, Kunming, Yunnan \\ Province, P. R. China 650201 \\ ${ }^{2}$ School of Geography, University of Plymouth, Plymouth, Devon PL4 8AA, United Kingdom \\ Corresponding author, Address: School of Information and Engineering, Yunnan \\ Agricultural University, Kunming, Yunnan Province, P. R. China 650201, Tel: +86-871- \\ 5823986, Fax: +86-871-5227717,Email:myduanx@yahoo.com
}

\begin{abstract}
Information and Communication Technology (ICT) development strategy in Chinese rural areas is an indispensable part of national development strategies. This paper reviews the ICT framework in agriculture and rural areas launched by the Department of Agriculture in China. It compares the rural ICT policies and strategies between China and the European Union (EU). The ICT development strategy framework is analyzed based on the situation in Chinese rural area and the experiences of the EU. Some lessons and suggestions are provided.
\end{abstract}

Keywords: ICT, ICT policy and strategy, ICT initiative, Internet, rural areas

\section{INTRODUCTION}

China is a big agricultural country with $57.01 \%$ of the total population living in rural areas. The toughest challenges related to agriculture, countryside and farmers, which will determine the current society development. The lack of information in rural areas is a dominant factor resulting in the digital divide, which is seriously hampering the rural development. The digital divide is the ever-growing gap between those

Please use the following format when citing this chapter:

Duan, M., Warren, M., Lang, Y., Lu, S. and Yang, L., 2009, in IFIP International Federation for Information Processing, Volume 295, Computer and Computing Technologies in Agriculture II, Volume 3, eds. D. Li, Z. Chunjiang, (Boston: Springer), pp. 1835-1844. 
people and communities who have access to information technology and those who do not. ICT is basically information-handling tool, and particularly refers to the Internet in this paper. The rural ICT policy and strategy plays a key role in promoting an intensive and wide use of ICT, driving economic development and improving quality of life in rural areas.

It is the main aim of China's 11th Five-Year plan (2006-2010) to build a socialist new countryside and to build a socialist harmonious society. Following the Plan, National ICT Development strategy (2006-2010) was published, with an emphasis on speeding up political, economic, cultural and social development through ICT. Based on the strategies, the ICT framework in agriculture and rural areas was developed in 2007. It aims to provide information services for farmers, to narrow the digital divide and help move forward the development of rural economy and society.

\section{ICT DEVELOPMENT STRATEGY IN RURAL AREAS}

The digital divide is the result of the inability of a large portion of the world's population to access and effectively use ICT and the potential benefits they enable (UNDP, 2001). The rural issue arises from the population in rural areas to be at a disadvantaged position with respect to ICT. This digital disadvantage often results from socio-economic disadvantage, and in turn makes the latter worse: the digital vicious cycle (Warren, 2007). However, "any online process, whether transactional or merely informational, which substitutes for one involving physical movement is likely to be of greater utility to rural than to urban populations, especially given the increasing tendency of governments... to reduce or fail to make provision in areas of dispersed population" (Furuseth, 1998 ).

ICT development strategy is the plans based on the selection of scenarios and options for applying ICT to national development, ensuring the greatest possible diffusion of ICT, commensurate with national needs, ambitions, specificities and concerns (Labelle, 2005). According to the definition, ICT development strategy in rural areas can be seen as plans for the use of ICT in rural areas and an indispensable part of national development strategies. It needs to be integrated into broad development concerns and mainstreamed into all aspects of society and of development planning, as well as taken into account local, national and international issues. The ICT strategy provides a commentary on the continuing development and use of ICT in rural area. 

Areas

\section{ICT INITIATIVES AND THE LISBON STRATEGY IN EUROPEAN UNION}

Lisbon strategy is a wide range of policies launched by the European Union. It aims to make Europe more dynamic and competitive and focuses on growth and jobs in the knowledge-based economy. To achieve the goal of the Lisbon Strategy, eEurope and i2010 were released to build a fully inclusive Information Society across the Europe. They are the political initiatives and actions to bring the benefits of the Information Society to the reach of all Europeans, based on the widespread use of ICT in public services, SMEs and households. In general eEurope had been strong on bringing citizens and businesses online and establishing a framework within which the knowledge economy can grow. i2010 is translating these achievements into tangible economic benefits, higher productivity, improved quality of service, greater social inclusion and non-inflationary growth (European Commission, 2002).

Rural development is also central to the Lisbon process. Lisbon strategy encourages take-up or diffusion of ICT by extension of broadband coverage to help promote new ways of selling and dealing with risk. It assists village ICT initiatives by providing combination of computer equipment, networking and training and facilitates on-farm tourism through ICT use by improving booking systems, promotion and links with recreational activities (European Commission, 2000).

\section{ICT IN CHINESE RURAL AREAS}

\subsection{ICT development}

There will be a huge development of ICT in rural areas. The speed of Interne in rural areas has surpassed that in the city, and the annual growth rate reached $127.7 \%$, far higher than that of the urban user, which was $38.2 \%$ (CNNIC, 2008). Some students, entrepreneurs, farmers start surfing on the Internet by mobile phone to obtain useful and real time information. More and more farmers and agricultural entrepreneurs are realizing the importance of information. They make an effort to acquire related information to guide their plan, production and sale by using ICT while confront an intensive competition.

The infrastructure is being improved because of the continuous economic growth, which provides a good environment of ICT development in rural areas of China. The average annual rate of growth has exceeded $10 \%$ since 
2004, and the level of resident income has increased a lot. A large number of capitals with $\$ 9.8$ million construction funds and $\$ 1.3$ million maintenance fees were put into the projects of rural ICT infrastructure (CNNI, 2008). For example, the project of Phone for Every Village started in 2004 had made the phone available to $99.5 \%$ of administrative villages. A series of policies has been published to support the adoption and use of ICT in rural areas. It was put forward to quicken the construction of agricultural informatization, to enhance the rural ICT infrastructure, and to innovate rural service mode in 2006 for the first time. It is also the first time for government to issue the ICT framework in agriculture and rural areas as a general policy and strategy in 2007.

\subsection{Problems and Challenges}

There are some problems existing for services to rural areas in spite of improving infrastructure and sound governmental policies. The following analysis is to revolve around the topic of providing services.

A good connectivity is the prerequisite to providing services for farmers. Even the infrastructure of ICT can reach most of villages, but it is not easy to solve the issue of last mile. One factor is related to the income level. The resident income in rural area is $\$ 414$, only $1 / 3$ of that in urban areas in 2007 , which determine the lower rate of owning the hardware device like phone, computer. Another factor affecting the access to the Internet is education level and skill. Lack of knowledge of computer or network keeps people in rural areas away from the Internet. The Internet penetration in rural areas is only $7.1 \%$ compared with $27.3 \%$ in urban areas (CNNI, 2008). The farmers have used to the traditional way to acquire the information and services, and have no awareness that they can benefit from the Internet.

The lack of useful information and services puts farmers at a disadvantage, which widen the gap between the urban and rural areas. The practical and appropriate content is the most valuable for farmers. However, there are so many irrelative and duplicate resources on agricultural websites. Only $31.2 \%$ of official resources on agriculture have established online. The online content obtained by farmer just account for $1.8 \%$ of total information (Yang, 2007). Most of rural Internet users only take the Internet as a chatting tool and recreation tool, with shallow Internet application. Respectively $86.4 \%$ and $76 \%$ of them use the online music and online film and TV functions (CNNI, 2008). 


\section{ANALYSIS OF ICT DEVELOPMENT STRATEGY FRAMEWORK IN CHINESE RURAL AREAS COMPARED WITH THAT IN THE EU}

\subsection{ICT strategy comparison between China and EU}

There is not a separate rural ICT strategy in EU, but it is covered in eEurope and i2010. China is a developing country, and can learn a lot from the formulation of ICT strategy in EU. With respect to ICT development strategy, the past of that in EU is the present in China, and the present in EU is the future of China.

\subsubsection{Aim and objective}

Table 1. Aim and objective

\begin{tabular}{|c|c|c|c|c|}
\hline & $\begin{array}{l}\text { Strategy or } \\
\text { initiative }\end{array}$ & During & Main aim & Objective and action \\
\hline \multirow{3}{*}{$\mathrm{EU}$} & eEurope 2002 & $2000-2002$ & $\begin{array}{l}\text { Extending the Internet } \\
\text { connectivity }\end{array}$ & $\begin{array}{l}\text { A cheaper, faster and secure Internet } \\
\text { Investing in people and skills } \\
\text { Stimulate the use of the Internet }\end{array}$ \\
\hline & eEurope 2005 & $2002-2005$ & $\begin{array}{l}\text { Promoting modern online } \\
\text { public service and dynamic } \\
\text { e-business environment }\end{array}$ & $\begin{array}{l}\text { e-government } \\
\text { e-learning } \\
\text { e-health services } \\
\text { e-business }\end{array}$ \\
\hline & i2010 & 2005-2010 & $\begin{array}{l}\text { Achieving inclusion and a } \\
\text { quality life }\end{array}$ & $\begin{array}{l}\text { A single European information space } \\
\text { Innovation and investment in research } \\
\text { Inclusion, better public services and } \\
\text { quality of life }\end{array}$ \\
\hline China & ICT in rural areas & $2007-2015$ & $\begin{array}{l}\text { Providing information } \\
\text { service and advance rural } \\
\text { development }\end{array}$ & $\begin{array}{l}\text { promote modern agriculture advance } \\
\text { public service and society } \\
\text { management build and improve } \\
\text { information organization }\end{array}$ \\
\hline
\end{tabular}

In the EU, under the guidance of the Lisbon Strategy, there have been three separate ICT development policies and strategies: eEurope 2002, eEurope 2005 and i2010. The ICT policy and strategy framework in agriculture and rural areas (2006-2015) was published by the Department of Agriculture, which was based on the National ICT development strategy (2006-2020).

From table 1, it can be seen the priorities are different at three stages, but they are related and supportive. eEurope 2002 emphasizes the connectivity of Internet. eEurope 2005 is shifted to providing attractive services and applications, and encourage organizational change. i2010 is the EU policy framework for the information society and media, with purpose of harnessing the potential of ICT to drive innovation and productivity in Europe. The main aim of the Chinese rural ICT strategy is to provide the 
public service and society management, and meet the need of building the modern agriculture and constructing a new socialist country.

Strategies are achieved using a variety of tools, in which comparative analysis, including studying and comparing international experience and best practices, is a useful tool. The ICT strategies in the EU are continuous and sustainable. The late initiative is built on the previous. Only after reviewing and evaluating the action, can a new strategic framework be proposed. To certain degree the aim of Chinese strategy is similar to the eErurope 2005, but the use of ICT in Chinese rural areas far fall behind that in the EU.

\subsubsection{Four elements in ICT strategy}

The main components of ICT strategy framework in Chinese rural areas are infrastructure, information resource, human capacity, service and application system, rule system and operation mechanism. The structure can be simplified to four basic elements in ICT strategy, consisting of infrastructure, human capacity, service and environment. They have an impact on economy, politics, culture and society in rural areas.

In a sound environment of legislative framework and mechanism, people use services on Infrastructure to achieve their goals. The following table 2 compares the ICT strategies in the EU and China in terms of four elements.

The strategies regard infrastructure a key part of ICT. eEurope 2002 built a cheaper, faster and secured Internet, and increased the number of citizens and businesses connected to the Internet. It extended the Internet connected to schools, universities, research institution and business. Since 2005, due to transforming to broadband connection and adopting multi-platform technology, the infrastructure had greatly improved. i2010 make the network faster and more security by new digital convergence techniques.

The strategies invest in human capacity. More emphasis was put on human capacity because of the new requirements for information society skills and the problem of skills shortagese. One of objectives of eEurope 2002 was to invest in people and skill. They included three actions: European youth into the digital age, working in the knowledge-based economy and participation for all in the knowledge-based economy. eEurope 2005 and i2010 further to enhance the education and skill by e-learning and e-training. 

Areas

Table 2. Four elements in ICT strategy

\begin{tabular}{|c|c|c|c|c|}
\hline & Infrastructure & Human capacity & Service & Environment \\
\hline eEurope 2002 & $\begin{array}{l}\text { Cheaper, faster, secure } \\
\text { Internet }\end{array}$ & $\begin{array}{l}\text { Invest in people an } \\
\text { skill }\end{array}$ & $\begin{array}{l}\text { Stimulate the use of } \\
\text { Internet }\end{array}$ & $\begin{array}{l}\text { Communications network } \\
\text { and e-Commerce }\end{array}$ \\
\hline eEurope 2005 & $\begin{array}{l}\text { Broadband Multi- } \\
\text { platform }\end{array}$ & $\begin{array}{l}\text { Improve } \\
\text { participation and } \\
\text { enhance skill }\end{array}$ & $\begin{array}{l}\text { Provide online public } \\
\text { services and private } \\
\text { services }\end{array}$ & Private investment \\
\hline i2010 & Digital convergence & Digital skill & $\begin{array}{l}\text { offer communications, } \\
\text { rich content and digital } \\
\text { services }\end{array}$ & $\begin{array}{l}\text { Electronic communication } \\
\text { Audio-visual }\end{array}$ \\
\hline $\begin{array}{l}\text { Rural areas in } \\
\text { China } 2007\end{array}$ & Internet + Broadband & $\begin{array}{l}\text { Distant education, } \\
\text { Skill training }\end{array}$ & $\begin{array}{l}\text { Agricultural extension of } \\
\text { science and technology, } \\
\text { e-government }\end{array}$ & \\
\hline
\end{tabular}

Service is put in the centre of EU ICT strategies, which is an essential ingredient to drive ICT development. eEurope 2002 stimulated the use of Internet by e-commerce, government online, health online and digital content for global networks. eEurope 2005 offered interactive public services including e-government, e-health and e-learning, and encouraged ebusiness by private sector. i2010 provides affordable and secure high bandwidth communications, rich and diverse content and better digital services, and quality of life.

The regulatory and legislative framework ensures the development of ICT. In eEurope 2002, legislative framework was put forward to reinforce the competition of market, to reduce the price and stimulate the innovation. eEurope 2005 made policy to encouraged the private sector to invest broadband infrastructure. i2010 established legal framework for audio-visual services.

\subsection{Lessons learned from ICT strategy in EU}

First, cheap, fast and secure Internet is provided. Even in the EU, the legislative framework is used to lower the cost through the market competition. Low level of income prevents most of Chinese farmers connecting to the Internet. Only the Internet cost is affordable for citizens in rural areas, can the Internet connectivity be extended. Additionally, it is necessary to improve the infrastructure with the new technology. The network was gradually transformed to broadband in the EU since 2005. IP addresses also had transited to Internet Protocol version 6 (IPv6). All the updating makes the Internet more attractive to the user who can use the Internet easily.

Second, people and skill is the most important factor in ICT strategy. The low level of education and skill keep the resident in rural areas away from the Internet. The ICT strategies in the EU pay more attention to the education and training. Education will make a major contribution to developing new skills, and the skills will help people take advantage of the 
potential of the Internet fully. From the beginning, EU connected the schools to the Internet to promote education, and then persisted in investing in people and skill.

Third, the new content, information and service are the centre of ICT strategy. EU strategies encourage providing the basic and cheaper service to citizens by stimulating the use of the Internet. After that, the new attractive content, service and application are fostered and created with development in multi-platform access, interactive software. People can be access to digital content and media services through PC, digital TV and mobile. It is a priority for the ICT strategy in rural area to offer the practical, cheaper and attractive service.

Fourth, the formulation of ICT strategies is emphasized. The process involves in identifying priority areas, developing action plans, implementing and evaluating the actions. All of ICT strategies of the EU support to realize the Libson aim of growth and jobs. A series of programs and projects are implemented to reach the objectives of the action plan, such as Research Framework Programme and the Competitiveness and Innovation Programme. Mid-term review and annual report are used to analyze and assess the progress in the implementation so that the strategy remains up to date with the rapidly changing ICT environment. In china, the department of making policy is separated from the department of implementation. Therefore evaluation is critical to ensure an achievement of the ICT policy and strategy in rural areas in China.

\subsection{Suggestions}

ICT policy and strategy in rural areas of China is a general national framework, so the regional context is considered. Different regional strategies should be reformulated and facilitate the exchange of experience, of good practices and demonstration projects, as well as of sharing the lessons from failures. The rural areas in China are divided into three categories which are eastern developed regions, middle medium developed regions and western less developed regions (Mei, 2007). Based on the regional strategy, provincial and county ICT strategies should be launched in different rural areas. They interact and support each other to ensure the ICT strategies of different level are carried out efficiently and achieve their aims.

It is necessary for government to accelerate the setting up of an appropriate legal framework and policy about ICT use in rural areas at national and regional level, which will provide a sound development environment of ICT policy and strategy. The regulatory can encourage the market competition to reduce the cost of access to the Internet and obtain the online public services. The policy of investment in ICT of rural areas will 
promote more and more rural citizens to surf on the Internet, to get more education, skill training and useful information and services. The legislative framework encourage private sector invest in rural ICT and get more fund support, since only the government investment is not enough to improve the infrastructure, human capacity and service.

The organizations of two-level information service are constructed in county and village. The agricultural information service system is top-down, multilevel and complicated, including too many departments. However, the two kinds of information service points have integrated multi-functions, which can manage the county and village, share the information, converge service, and provide the training and entertainment. For the disadvantage farmers who are illiterate or lack of the IT skill, the local information organization can help and guide them obtaining the useful information and service. The service points manage local content and information, making farmer to participate and benefit from the use of ICT.

\section{CONCLUSION}

ICT development strategy framework in Chinese rural areas involves in four basic elements of ICT development strategy and identify the services is the priority. It is a universal guidance of regional and local rural ICT strategies. Lessons from the ICT strategy of the EU are helpful to form the rural ICT strategy and plan action. On the one hand, it is very important to provide cheap, fast and secure Internet, invest people and skill, and offer content, information and service. On the other hand, reviewing, evaluating and update the strategy is indispensable. The rural ICT strategy of China should consider regional context, legal framework and policy, and information service organization.

\section{ACKNOWLEDGEMENTS}

I would like to dedicate the accomplishment to my supervisor Martyn Warren, the director of Rural Futures Unit, University of Plymouth, who directed and helped me during my staying in the UK. I gratefully acknowledge the support from my colleagues at Yunnan Agricultural University. Yunnan Provincial Department of Education funded me to do research of ICT in the UK. 


\section{REFERENCES}

China National Network Information Center (CNNIC). Survey Report on Internet Development in Rural China 2008. 2008. http://www.cnnic.cn/uploadfiles/pdf/2008/1/17/ 104156.pdf

European Commission. 2000. http://www.europe.canterbury.ac.nz/courses/uro227/ special_en.pdf

European Commission. 2002. Information Society Benchmarking Report 2002. http://ec.europa.eu/information_society/eeurope/i2010/docs/benchmarking/051222_final_b enchmarking_report.pdf

Furuseth, O (1998). Service provision and social deprivation in the geography of rural change. Ilbery, B (ed). Harlow, UK, Pearson: 233-256.

Labelle, R. ICT Policy Formulation and e-Strategy Development. Elsevier, India. 2005. http://www.apdip.net/publications/ict4d/ict4dlabelle.pdf

MEI Fanquan. ICT development strategy and mode in Chinese rural areas. China Rural Science and Technology 2007, (12), 20-21(in Chinese)

UNDP Education Office. Information Communication Technology for Development Essentials: Synthesis of Lessons learned, 2001, http://www.apdip.net/ documents/policy/ actionplans/ Essentials05092001.pdf

Warren, M.F. The digital vicious cycle: links between social disadvantage and digital exclusion in rural areas. Telecommunications Policy 2007, 31, (6-7), 374-388.

YANG Bao-zhu. The research of development strategies for agricultural informatics and informatization of agriculture in China. Agricultural Network and Information 2007, (9), 48. 